\title{
An Analysis of the Socioeconomic Conditions of the Rural People based on Caste -Implications for Suitable Watershed Management in the Kaski District, Nepal-
}

\author{
Rajendra Prasad Lamichhane*1, Masahiro Amano*2, Takeshi Kadota*3 and Akihiko Sasaki*4
}

\begin{abstract}
Watershed management is important in Nepal to stabilize the physical environment and to improve the livelihood of watershed residents. Recently, people's participation has been a fundamental government policy in forest/ watershed conservation. Although participation of all the stakeholders is necessary for the success of the program, their participation largely depends upon the extent of the reflection of their needs in watershed management activities. With caste-related discrimination still prevalent in Nepal, this paper attempted to identify the caste differences as reflected in their socioeconomic condition. The findings revealed that there are wide gaps between the caste/ethnic groups regarding their socioeconomic condition. The gap is particularly wide between the higher caste/ethnic group and the lower castes. Radar chart analysis showed that the local people are more concerned with socioeconomic problems compared to the natural resource aspects. Regression analysis showed that shortage of cereals is the biggest positive predictor variable of the concern for food availability. The proportion of illiterate households and livestock population are the other predictor variables. On the other hand, the amount of paddy produced, walking distance to piped water in the wet season, and walking distance to fuelwood forest are the negatively related predictor variables of the concern for food availability. Total area of Bariland (rainfed farmland) is the most important negative predictor variable for concern for fuelwood availability, followed by the area of Khetland (irrigated farmland). Walking distance to fuelwood forest, production of maize and membership in community forest are the positive predictor variables. The differences in socioeconomic conditions have deep implications for the participatory approach, as conflict of interest may arise between the groups with different socioeconomic backgrounds. It is recommended that such differences in watershed management planning be addressed so as to gain broader participation from all the stakeholders.
\end{abstract}

Keyword: people's participation, caste, watershed management, socioeconomic condition

\section{INTRODUCTION}

Nepal, a small mountainous country covering an area

\footnotetext{
${ }^{* 1}$ Doctoral Program, Department of Agriculture and Life Sciences, Faculty of Forest Science Laboratory of Forest Management, University of Tokyo e-mail: rami @fr.a.u-tokyo.ac.jp

${ }^{* 2}$ Department of Forest Management, Forestry and Forest Products Research Institute

*3 (Late) Ex-JICA Expert.

${ }^{* 4}$ Nippon Koei
}

of $147,481 \mathrm{~km}^{2}$, has a population of $18,491,097$ (CENTRAL Bureau of Statistics, 1997). More than $80 \%$ of the economically active population is involved in farming. Nepal consists of three geographical regions-the Terai (plain area), the Hills and the Mountains (Fig. 1). Forestland is an integral part of the farming system in the Hills of Nepal. A feature of the integral relationship between the forests and the farming system in the Hills is the significance of watershed conservation in Nepal.

However, past forest policies failed to recognize this relationship, and were generally counterproductive in forest/watershed conservation. All forestlands were brought 


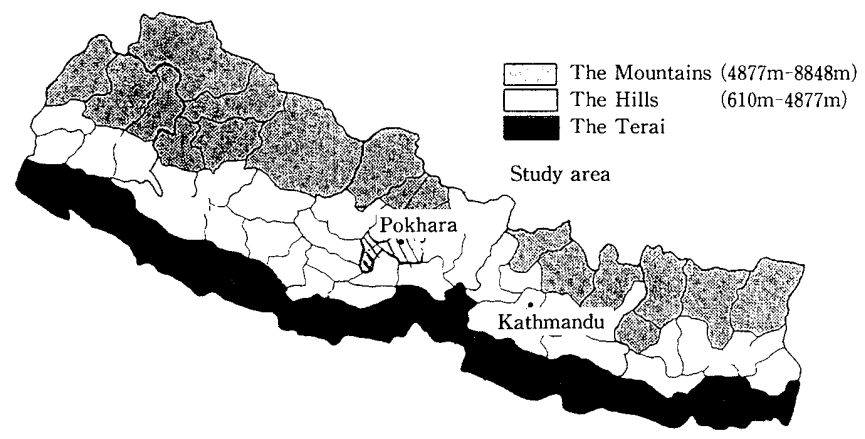

Fig. 1 The Geographical regions of Nepal

under government control (MAHAT et al., 1986) and state ownership was guaranteed through legal arrangements. The local people; however, continued to use the forest resources from the national forest, even though it was illegal.

The continuous exploitation of forests resulted in a decrease in the forest area in the Terai and the degradation of watersheds in the Hills. His Majesty's Government (HMG) of Nepal realized that forest/watershed conservation could not be achieved by the government alone; and, there was a need for involvement of local people (NATIONAL Forestry Plan, 1976, as quoted by Bajracharya, 1992).

Even though the caste system was legally abolished in 1963, caste-based discrimination is still alive in Nepal. Since it is important for all sections of the society to take part in watershed management activities, it is useful to study the socioeconomic condition of various caste/ethnic households for a more pragmatic watershed management approach

The main objective of this paper is to analyze the socioeconomic condition of the caste/ethnic households in the Kaski District and to discuss its implications for watershed management in the context of the current participatory approach.

\section{WATERSHED MANAGEMENT IN NEPAL}

Terrace construction on the hill-sides and planting of fodder and fuelwood trees are some of the numerous traditional watershed management practices in the Hills. However, at the government level, more concerted efforts started after the establishment of a separate Department of Soil Conservation and Watershed Management (DSCWM) ${ }^{* 5}$ in 1974. Watershed management is one of the six primary components of the Master Plan for Forestry Sector (MPFS, 1989). Over the years, the Department has

\footnotetext{
${ }^{* 5}$ Then Department of Soil and Water Conservation
}

experienced a major paradigm shift in approaches to watershed management.

Past watershed management approach

Until the late 1980s the Department focused on the large watersheds, implementing activities throughout the watershed area. The operational approach was on a project basis and many agencies were involved in carrying out various activities.

Further there was more emphasis on the erosion control aspects such as gully control, landslide treatment, torrent control etc. Work was carried out in the field either by directly hiring local laborers or by operating through contractors. The beneficiaries were scarcely involved (MeIman et al, 1985; Shakya et al., 1991 quoted by Bogati, 1996). The projects contributed almost all the costs required for watershed management activities and people's participation was non-existent

Integration among various line agencies and effective mechanism for involvement of local people were found to be lacking in the implementation of such large watershed projects. The implementation strategy consisted of topdown planning, implementation and monitoring of watershed projects. This approach did not encourage farmers' participation and hence proved to be unsustainable (W AGLEY, 1997).

\section{Current watershed management approach}

While most of the projects were implemented on a broad watershed basis, some projects, which adopted a different approach, were already demonstrating some promising results at the grass-roots level in the early 1990 s. The Begnas Tal Rupa Tal Watershed Management Project (BTRT/WMP) jointly implemented in the Kaski District by the DSCWM and CARE International, was one such Project. The Begnas and Rupa lake watersheds, the working area of the Project, consist of $19 \mathrm{~km}^{2}$ and $30 \mathrm{~km}^{2}$ respectively. The Project adopted people's participation as 
its fundamental strategy and was considered as a successful project in terms of contribution of local people and ownership of the completed activities (Bogatı,1996).

Lessons from such projects; persistent financial and manpower constraints; the need to produce more visible impacts in a short time, and further strengthening the mechanism of people's participation, entailed shifting to the sub-watershed approach. At present, functional subwatersheds of $5-25 \mathrm{~km}^{2}$ are identified for management with emphasis on people's participation (ACHET,1998). The DSCWM implements a wide range of watershed management activities such as gully treatment, torrent control, conservation planting, fruit and fodder tree planting, training, extension etc. which are broadly categorized as:

- Land Use Planning

- Land Productivity Conservation

- Development Infrastructure Protection

- Natural Hazard Prevention

- Community Soil Conservation

In 1993, the 'Guidelines for People's Participation in Soil Conservation and Watershed Management' was promulgated by the Department. The Guidelines makes it mandatory to work through the Users' Groups (UG) for detailed planning of activities, implementation, maintenance and follow-up and benefit sharing. However, the willingness of the people to participate in the watershed management activities also depends upon the significance of the activities in their daily life. Hence, it is crucial to understand the people's concerns and their socioeconomic condition in order to formulate more pragmatic watershed management policies. Although the guidelines are silent about the ultimate objective of people's participation, they did however provide an impetus for strengthening the participatory watershed management approach in Nepal.

Unlike in the past when all the cost was borne by the projects, now the local people have to provide unskilled labor, and the projects or the DSCO (District Soil Conservation Office) provide construction materials and cash for the skilled labor. Therefore, contribution of unskilled labor by the local people is a condition in the current watershed management approach.

Nevertheless, despite the formulation of more progressive policy measures, there are still problems to overcome in the present situation. The tradition of fixing targets is still pursued. Despite the wide flexibility demanded by the participatory approach, all the watershed management activities are fitted into the predefined framework. The voice of high caste and elite dominates the users' groups (Kayastha, 1997; Oltheten, 1995).

However, recently the need for a paradigm shift from the physical target-oriented development strategy to one focusing on process strengthening and capacity building of the local people has been emphasized (Sharma, 1997; NaGAme, 1997; Danida 1996; Oltheten,1995). In this con- text, the definition of watershed management given by Sharma et al. (1997) deserves particular attention.

Sustainable participatory integrated watershed management is defined as utilization and conservation of land, water, and forest resources, at farm household and community (or given watershed) level for continuously improved livelihood and human development (Sharma et al., 1997)

People's participation is a rich concept which is interpreted differently in different situations (WORLD BANK, 1996; OLtheten, 1995). However, two aspects are found most commonly in descriptions of people's participation. The first is the involvement of the disadvantaged group who have been previously excluded in the development process; and, the second is the stakeholders' influence and control of the development processes which affect them. (Bogati, 1995; FAO, 1991; Oltheten, 1995; Sharma et al., 1997; W ORLD BANK 1996). Following this it can be concluded that in the people's participation process, people's empowerment is vital so that they can take initiatives and contribute to and control the development process.

\section{METHODOLOGY}

This study is mainly based on the data obtained from the socioeconomic survey conducted by Japan International Cooperation Agency (JICA) in the Western Hills of Nepal. Observations made by this author in the field surveys in one of the Village Development Committees (VDC), the lowest administrative unit in Nepal, have also been utilized wherever appropriate. A socioeconomic baseline survey for the JICA Development Study on Integrated Watershed Management in the Western Hills of Nepal was carried out from December 1995 to September 1996. This study was conducted in two districts, namely Kaski and Parbat. It covered 19 VDCs in the Kaski district. The area covered by the survey is approximately 29,521 ha.

The survey comprised a Household Survey, which included a survey of the household heads; and a Household Members Survey, which included a survey of the household members. Approximately 4,668 households and 10,624 household members were surveyed in the Kaski district (JICA/HMG, 1998).

Survey method

The survey method consisted of structured questionnaires for the household survey and household member survey. An administrative survey was conducted through contact with key informants such as school teachers, local political leaders, leading farmers etc. The survey team consisted of 5 groups, each having 6 enumerators and a group supervisor. These survey groups were supervised by the Field Supervisor. The information collected by the 
enumerators was verified by the Group Supervisors and the Field Supervisor.

\section{CASTE SYSTEM IN NEPAL}

As it is diverse in geographical and ecological setting, Nepal is inhabited by various caste and ethnic groups with diverse culture, social customs and life style. The caste system was legalized in the entire country in 1854 (BISTA, 1991). Although it was legally abolished in 1963, the traditional taboos based on caste are still prevalent in the society.

Caste composition in the Kaski district

Kaski district is inhabited by various caste households e.g. Brahmin, Chhetri, Thakuri, Gurung, Magar, Kunwar, Kami, Damai, Sarki etc. In Kaski district, the sample households consist of $48 \%$ Brahmin/Chhetri, 17\% Gurung/Magar/Kunwar and 23\% Damai/Kami/Sarki caste households. The rest consist of various other castes. For the purpose of this study the sample households have been categorized into the following three groups, which comprise more than $88 \%$ of the sample population.

\section{i) Brahmin/Chhetri $(\mathrm{BC})$ :}

Brahmins rank highest in the caste hierarchy and along with Chhetris they form a majority of the influential and wealthy people of traditional Nepal (BISTA, 1996). The main occupations of Brahmin and Chhetri are farming and government service.

\section{ii ) Gurung, Magar and Kunwar (GMK):}

Gurung and Magar are ethnic groups. Gurung and Magar are famous for their service in the army. They generally live in the upland and many people work away from home.

\section{iii) Kami, Damai, Sarki (KDS):}

These are the lower caste people, also known as the occupational caste. Kami, Damai and Sarki are blacksmiths, tailors and cobblers respectively. They are considered as untouchables by the rest of the social groups. The situation of low caste is characterized by their ownership of only marginal cropland or no land at all, serving higher castes through trade of skills for food, lack of access to credit, and poor nutrition and education (Evans, 1997).

\section{SOCIO-ECONOMIC CONDITIONS OF THE CASTE/ETHNIC HOUSEHOLDS}

The socioeconomic variables considered for the purpose of analysis are land ownership, source of cash income, fuelwood, drinking water, livestock, crop production and

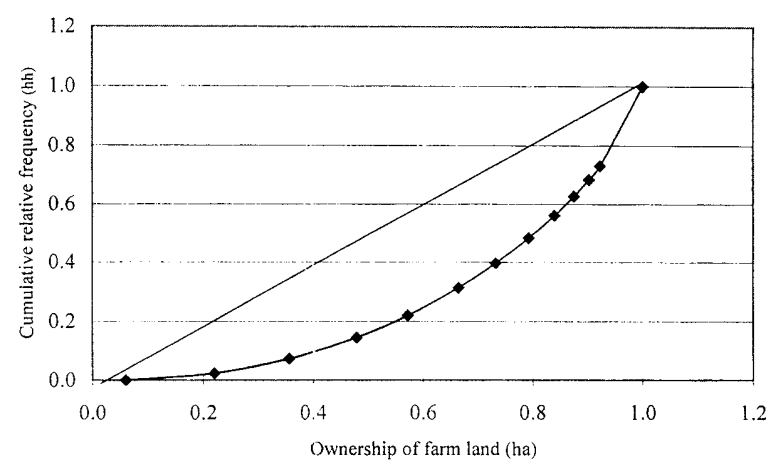

Fig. 2 Ownership of farmland by sample households

people's concerns.

Land ownership by caste/ethnic households:

Farmland in Nepal is basically categorized as Khetland (irrigated lowland) and the Bariland (rainfed upland). Rice, maize, wheat etc are grown in the Khetland, whereas maize, wheat, mustard, millet etc. are grown in the Bariland. Fodder trees are mostly grown in the Bariland. The size of the landholding determines food production, animal fodder, production of crop residues, number of livestock to be supported and overall livelihood of a family.

i ) Overall land ownership pattern in the study area:

The inequality of land ownership among the households in general is illustrated in Fig. 2. It shows that about $80 \%$ of the households own approximately half of the farmland whereas the remaining $20 \%$ own the other half showing a great disparity.

ii ) Households without farmland:

The number of households without farmland differs significantly among the caste/ethnic groups. About $1.6 \%$ of the $\mathrm{BC}, 5.5 \%$ of the GMK and $13.2 \%$ of the KDS households do not own any farmland.

iii) Ownership of Khetland:

Both the $\mathrm{BC}$ and the GMK own a significantly greater area of Khetland than the KDS. Ownership of Khetland is a status symbol in Nepal. On average, BC households own 0.43 ha of Khetland followed by 0.34 ha by GMK and 0.07 ha by KDS households. About $70 \%$ of the KDS households do not own any Khetland.

iv) Ownership of Bariland:

The KDS households own an average of 0.09 ha of Bariland compared to 0.19 ha owned by the BC and GMK households. Households that do not own any Bariland comprise $15.5 \%$ of total households for the KDS, but only 9.3 and $6.7 \%$ for the $\mathrm{BC}$ and $\mathrm{GMK}$ respectively. 
Table 1 Source of cash income of caste/ethnic households

\begin{tabular}{lccc}
\hline Source of cash income & BC & GMK & KDS \\
\hline People's concern for cash income (score & 78 & 77 & 92 \\
Remittance from family members & 18.2 & 28.8 & 18.8 \\
Wage from temporary jobs & 10.2 & 3.6 & 14.3 \\
Private business & 5.9 & 4.0 & 5.2 \\
Pension & 6.3 & 37.4 & 3.4 \\
Salary from permanent job & 21.8 & 7.2 & 2.4 \\
Selling livestock/Dairy products & 12.6 & 3.3 & 0.4 \\
Selling crops & 7.0 & 1.3 & 0.2 \\
Selling forest products & 0.7 & 0.4 & 0.0 \\
Others & 17.1 & 14.1 & 55.3 \\
\hline BC=Brahmin/Chhetri & & unit-\%hh \\
GMK=Gurung/Magar/Kunwar & & & \\
KDS=Kami/Damai/Sarki & & &
\end{tabular}

\section{Source of cash income}

The sample households derive their income from various sources such as selling crops, selling livestock and dairy products, pensions, salary from permanent jobs, remittance from family members, wages from temporary jobs, private business and other sources (Table 1). The 'other' sources of income include poultry farming, house rent, bank interest, wage labor, selling fruit, tailoring, mechanics, portering etc.

The major sources of income for the $\mathrm{BC}$ households are salaries from permanent jobs (22\%), remittances from family members $(18.2 \%)$, selling crops and livestock products $(20 \%)$. The GMK households derive most of their income from pensions (37\%) and remittances from family members $(29 \%)$. On the other hand the KDS households mainly derive their income from 'other sources' (55\%), mainly daily wage labor. They also depend on remittances from family members (19\%).

Members of all caste households have a generally high degree of concern for cash income. KDS household members have the highest degree of concern for cash income. This is justified by the fact that the $\mathrm{BC}$ and the GMK households have relatively stable sources of income such as salaries from permanent job and pensions, compared to the KDS households who are mainly dependent on wages from temporary jobs and other sources.

\section{Fuelwood}

Wood is the basic source of fuel in Nepal, supplying about $73 \%$ of the total energy consumption (CBS, 1996). More than $97 \%$ of the households in the Kaski district consider it as the major source of fuel for cooking, heating and other related needs. Fuelwood collection is an impor-
Table 2 Ownership of private trees by sample households

\begin{tabular}{lccc}
\hline Type of trees & BC & GMK & KDS \\
\hline Fodder trees & 21.1 & 17.2 & 5 \\
Fuelwood trees & 48.8 & 53.2 & 10.5 \\
Timber trees & 9.2 & 12.7 & 2.2 \\
Horticultural trees & 19.3 & 9.6 & 4.6 \\
\hline Total (no) & 98.4 & 92.7 & 22.3
\end{tabular}

$\mathrm{BC}=$ Brahmin $/$ Chhetri

GMK $=$ Gurung/Magar/Kunwar

$\mathrm{KDS}=\mathrm{Kami} /$ Damai $/$ Sarki

tant activity in the rural area. Depending on various factors such as ownership of private land, access to the community forest, supply of forest products from the private lands etc., villagers have to spend considerable time on fuelwood collection.

i) Fuelwood consumption:

In the Kaski district, average per capita consumption of fuelwood is $427 \mathrm{~kg}$ per year. High caste households consume $429 \mathrm{~kg}$, GMK consume $467 \mathrm{~kg}$ and KDS consume $422 \mathrm{~kg}$ of fuelwood per person per year.

ii ) Households purchasing fuelwood:

About $5.7 \%$ of the total households purchase fuelwood. There is not much difference among the caste/ ethnic groups regarding the purchasing of fuelwood-5.6, 5.3 and $6.4 \%$ for BC, GMK and KDS respectively. Per capita purchasing is highest among the GMK with $324 \mathrm{~kg}$, while the $\mathrm{BC}$ and KDS purchase $257 \mathrm{~kg}$ and $235 \mathrm{~kg}$ respectively.

iii) Walking distance to fuelwood forest:

The KDS have to walk approximately 65 minutes to reach the fuelwood forest compared to 48 minutes by the $\mathrm{BC}$ and GMK households.

iv) Ownership of private forest:

About $15 \%$ of the sample households own private forest. Approximately $20 \%$ of the BC households and $22 \%$ of the GMK households own private forest, compared to only $4.5 \%$ of the KDS households. About $64 \%$ of the total private forest is owned by the BC group, $25 \%$ by the GMK, $5 \%$ by the KDS households and $6 \%$ by others.

v ) Ownership of private trees by caste households:

Trees on farmland are an important source of fodder, fuelwood and fruits. The trees found on the farmland are mainly fodder trees, fuelwood trees, timber trees and horticultural trees. The caste households show a significant ownership pattern of these various types of trees.

The $\mathrm{BC}$ and GMK households own significantly more 
trees than the low caste. Table 2 shows that $\mathrm{BC}$ households own more fodder and horticultural trees, whereas the GMK households own more fuelwood and timber trees.

vi) Membership of community forest:

An analysis was done to examine whether there is any difference among the caste households pertaining to the membership of the community forest. The analysis showed that approximately $65 \%$ of all the caste groups have become members of the community forest and did not show a significant difference among the caste/ethnic groups.

Drinking water

\section{i) Source of drinking water:}

The main sources of drinking water in the Hills are piped water and spring water. A small proportion of the households also uses river water. There are four types of households based on their use of water in the dry and wet seasons-the households who use piped water in both seasons, households who use spring water in both seasons, households who use piped water in wet season and spring water in dry season, and the others who use piped water in dry season and spring water in wet season.

The GMK households have the highest percentage (76\%) using piped water in both seasons, followed by $63 \%$ of the BC households and $59 \%$ of the KDS households. About $22 \%$ of the $\mathrm{BC}$ households and $23 \%$ of the KDS households use spring water in both seasons compared to only $11 \%$ of the GMK households. As more water is available during the wet season, there are some households who use piped water in the wet season and spring water in the dry season. A very small proportion of the households use piped water in the dry season and the spring water in the wet season.

\section{ii ) Walking distance to drinking water source:}

There is significant difference in the walking distance depending on the type of drinking water source. Generally, the time taken to get piped water is shorter than for spring water. Similarly, it takes more time to fetch drinking water in the dry season than in the wet season. There is not much difference in the time for fetching piped water for drinking among the three caste groups. The range is between 12 minutes for the GMK households in the wet season and 17 minutes for the KDS households in the dry season.

However, there is remarkable difference in the time spent on fetching drinking water from the springs in the dry season. $\mathrm{BC}$ households spend the shortest time of about 14 minutes, followed by GMK spending about 35 minutes, while the KDS have to spend the most time i.e. 43 minutes to fetch drinking water from the spring in the dry season. GMK spend only about 13 minutes to fetch water from the
Table 3 Ownership of livestock by sample households

\begin{tabular}{lccc}
\hline Livestock & BC & GMK & KDS \\
\hline Cow & 1.01 & 1.01 & 0.57 \\
Buffalo & 1.54 & 1.23 & 0.82 \\
Goat & 0.68 & 0.67 & 0.23 \\
Sheep & 0.06 & 0.22 & 0.01 \\
Pig & 0.01 & 0.04 & 0.08 \\
Chicken & 2.87 & 2.96 & 1.57 \\
\hline
\end{tabular}

$\mathrm{BC}=$ Brahmin/Chhetri

GMK $=$ Gurung/Magar/Kunwar

KDS $=$ Kami/Damai/Sarki

spring in wet season whereas the BC and KDS spend 25.5 and 30.5 minutes respectively. In general, the KDS spend more time collecting drinking water than the other two caste groups.

iii) Walking distance to drinking water source for KDS households based on their location:

Further investigations were made to verify whether the time spent by KDS households differed with regard to their settlement in caste/ethnic majority wards. The KDS have to spend more time fetching drinking water regardless of their settlement in $\mathrm{BC}$ or GMK majority wards.

Livestock

Livestock is an integral part of the farming system in Nepal. In the Hills livestock rearing is considered as the second most important activity and it contributes about $27 \%$ of the total household income (RAJBHANDARI et al., 1981). In a cropping systems research study conducted in Pumdi Bhumdi VDC of the Kaski district, RANA et al. (1981) found that livestock contributed $24 \%$ of the household income. Five main reasons are given by the farmers for owning livestock (RANA et al., 1981):

1. Cash income

2. Food for household consumption

3. Draught power

4. Compost; and

5. Festivals and other occasions

Cattle, buffalo, goats, pigs, sheep and chickens are the major livestock and poultry raised by the caste households in the study area.

Table 3 shows that both the $\mathrm{BC}$ and the GMK households own more livestock than the low caste households. This is possibly because the supply of fodder and forage is greater on the farmland. This situation gives the high caste households easy access to animal products such as milk, meat, butter etc. A larger number of animals also means more manure for crop production.

Tree fodder is an important source of feed for the 
Table 4 Corrrelation matrix for people's concerns

\begin{tabular}{|c|c|c|c|c|c|c|c|c|c|c|c|c|c|c|c|c|c|c|c|c|c|c|}
\hline Concerns & 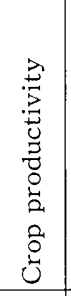 & 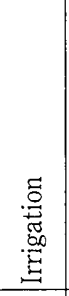 & 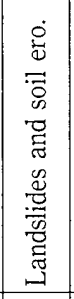 & $\frac{8}{8}$ & 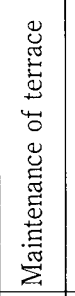 & 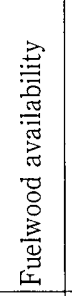 & 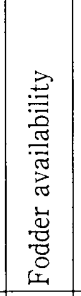 & 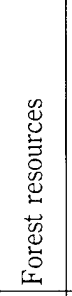 & 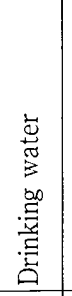 & 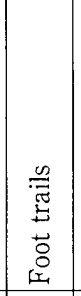 & 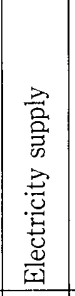 & 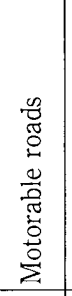 & 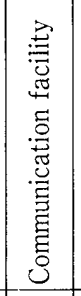 & 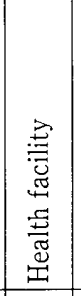 & 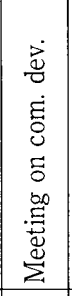 & 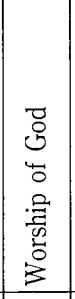 & 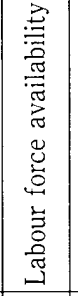 & 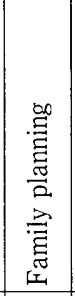 & 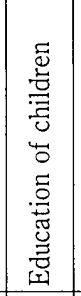 & 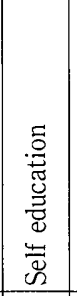 & 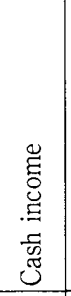 & 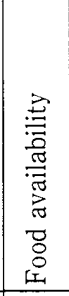 \\
\hline Crop productivity & & & & & & & & & & & & & & & & & & & & & & \\
\hline Irrigation & 0.49 & 1 & & & & & & & & & & & & & & & & & & & & \\
\hline Landslides & 0.20 & 0.03 & 1 & & & & & & & & & & & & & & & & & & & \\
\hline Flood & 0.19 & 0.02 & 0.73 & 1 & & & & & & & & & & & & & & & & & & \\
\hline Maint. Of terrace & 0.32 & 0.27 & 0.75 & 0.73 & 1 & & & & & & & & & & & & & & & & & \\
\hline Fuelwood & -0.06 & 0.00 & -0.25 & -0.25 & -0.31 & 1 & & & & & & & & & & & & & & & & \\
\hline Fodder & 0.17 & 0.16 & -0.26 & -0.15 & -0.20 & 0.80 & 1 & & & & & & & & & & & & & & & \\
\hline Forest resources & -0.03 & -0.07 & -0.11 & -0.22 & -0.33 & 0.74 & 0.49 & 1 & & & & & & & & & & & & & & \\
\hline Drinking water & 0.25 & 0.28 & 0.06 & \begin{tabular}{|l|}
0.09 \\
\end{tabular} & 0.18 & 0.06 & 0.18 & -0.14 & 1 & & & & & & & & & & & & & \\
\hline Foot trails & 0.42 & 0.32 & 0.26 & 0.33 & 0.46 & -0.28 & -0.04 & -0.23 & 0.39 & & & & & & & & & & & & & \\
\hline Electricily supply & 0.17 & 0.28 & -0.01 & 0.13 & 0.09 & -0.26 & 0.00 & -0.25 & 0.01 & 0.22 & 1 & & & & & & & & & & & \\
\hline Motorable roads & 0.37 & 0.48 & 0.08 & 0.11 & 0.22 & -0.15 & 0.09 & -0.18 & 0.20 & 0.46 & 0.42 & 7 & & & & & & & & & & \\
\hline Communication & 0.33 & 0.50 & 0.20 & 0.33 & 0.36 & -0.28 & -0.06 & -0.30 & 0.16 & 0.44 & 0.28 & 0.61 & 1 & & & & & & & & & \\
\hline Health facility & 0.11 & -0.28 & 0.19 & 0.16 & 0.07 & 0.04 & \begin{tabular}{|l|}
-0.07 \\
\end{tabular} & \begin{tabular}{|l|}
0.27 \\
\end{tabular} & -0.08 & 0.02 & 0.06 & -0.12 & -0.25 & +1 & & & & & & & & \\
\hline Meeting & 0.34 & 0.19 & \begin{tabular}{|l|}
0.07 \\
\end{tabular} & 0.19 & $0.22-$ & -0.50 & -0.29 & -0.39 & 0.12 & 0.45 & 0.42 & 0.32 & \begin{tabular}{|l|}
0.27 \\
\end{tabular} & 0.37 & & & & & & & & \\
\hline Worship of God & 0.18 & 0.38 & 0.10 & 0.24 & 0.21 & -0.21 & -0.06 & -0.14 & 0.23 & \begin{tabular}{|l|}
0.51 \\
\end{tabular} & \begin{tabular}{|l|}
0.08 \\
\end{tabular} & 0.16 & 0.49 & -0.30 & 0.15 & 1 & & & & & & \\
\hline Labour force & 0.16 & 0.30 & 0.22 & \begin{tabular}{|l|}
0.17 \\
\end{tabular} & 0.21 & -0.14 & -0.07 & 0.03 & 0.08 & 0.44 & \begin{tabular}{|l|}
-0.02 \\
\end{tabular} & 0.12 & 0.40 & \begin{tabular}{|c|}
-0.32 \\
\end{tabular} & -0.04 & 0.79 & & & & & & \\
\hline Family planning & 0.11 & 0.15 & 0.00 & 0.05 & -0.09 & 0.19 & 0.24 & 0.38 & 0.06 & 0.30 & 0.01 & 0.18 & 0.07 & 0.07 & -0.01 & 0.37 & 0.48 & & & & & \\
\hline \begin{tabular}{|l|} 
Education of childrean \\
\end{tabular} & 0.16 & 0.40 & 0.01 & -0.05 & 0.04 & -0.17 & -0.02 & 0.06 & 0.10 & 0.33 & 0.00 & 0.21 & 0.27 & -0.06 & 0.30 & 0.62 & 0.47 & 0.41 & 1 & & & \\
\hline Self Education & 0.18 & 0.00 & 0.28 & 0.19 & 0.09 & 0.13 & 0.09 & 0.46 & 0.00 & 0.14 & -0.10 & 0.00 & 0.02 & 0.27 & 0.08 & 0.25 & 0.36 & 0.41 & 0.29 & & & \\
\hline Cash income & 0.21 & 0.26 & $\mid-0.12$ & -0.01 & -0.01 & 0.38 & 0.54 & 0.30 & 0.19 & 0.19 & 0.14 & 0.33 & 0.07 & -0.31 & -0.28 & 0.18 & 0.16 & \begin{tabular}{|l|}
0.37 \\
\end{tabular} & 0.12 & 0.16 & 1 & \\
\hline Food vailability & 0.11 & 0.12 & 0.06 & $|-0.03|$ & 0.02 & 0.05 & 0.23 & -0.12 & 0.18 & 0.24 & 0.28 & 0.16 & -0.05 & $\mid-0.18$ & -0.04 & 0.21 & 0.18 & \begin{tabular}{|l|}
0.19 \\
\end{tabular} & 0.16 & -0.07 & 0.38 & \\
\hline
\end{tabular}

animals in the dry season when forage grass is not available. The ownership of more trees provides the high caste households with a base for supporting more animals than the lower castes.

\section{Crop production}

The main crops grown in the study area are rice, maize, wheat, mustard etc in the Khetland, and maize, wheat, millet etc. in the Bariland. Among the crops produced by various caste households, rice contributes the major proportion. However, it is the highest in $\mathrm{BC}$ households $(62 \%)$, then GMK households $(57 \%)$ and least $(45 \%)$ in the KDS households.

All castes produce maize in similar proportion $(18-21 \%)$. Wheat contributes little to total crop production $(4-7 \%)$. There is significant difference in the production of millet in the three caste households. Millet contributes $13 \%, 18 \%$ and $30 \%$ to total crop production for the $\mathrm{BC}$, GMK and KDS households respectively.

i) Use of chemical fertilizer in various crops:

Generally there are more farmers who apply chemical fertilizer in the Khetland than in the Bariland. More of the
$\mathrm{BC}$ households apply chemical fertilizer to all their crops than the other two castes. Generally the KDS households have the smallest percentage applying chemical fertilizer to their crops.

\section{ii ) Crop productivity:}

Productivity of rice in the Khetland indicates a clear difference based on caste. High castes have higher crop productivity than the lower castes. There are mixed results in the Bariland. GMK households have the highest crop productivity in the Bariland across all crops. Productivity of millet is higher in the GMK and KDS households than in the $\mathrm{BC}$ households.

Degree of concern of caste/ethnic households

As there are differences in the socioeconomic conditions of the caste households, so there are significant differences in the degree of concern expressed by the caste households. The degree of concern reflects the percent of household members who answered that they have "strong concern" for a particular issue.

The high caste $\mathrm{BC}$ households have a high degree of concern for cash income, food, crop productivity, irrigation 
Table 5 Category of concerns of sample houselds

\begin{tabular}{|c|c|c|c|c|}
\hline Main Category & Sub-Category & Present concerns & Degree of Variance & Radar chart variables \\
\hline \multirow{5}{*}{ A.Agriculture } & \multirow{2}{*}{ 1. Productivity } & a. Crop productivity & High & \\
\hline & & b. Irrigation & Medium & \\
\hline & \multirow{3}{*}{ 2. Erosion } & a. Landslides and soil erosion & High & * \\
\hline & & b. Flood & High & \\
\hline & & c. Maintenance of terrace & Medium & \\
\hline \multirow{3}{*}{ B.Forestry } & \multirow{3}{*}{ 1. Forestry } & a. Fuelwood availability & Very high & $*$ \\
\hline & & b. Foddder availabilty & High & \\
\hline & & c. Forest resources & Medium & \\
\hline \multirow{2}{*}{ C.Drinking water } & & a. Drinking water & High & $*$ \\
\hline & & b. Foot trails & High & \\
\hline \multirow{5}{*}{ D.Infrastructure } & & a. Electricity supply & Low & \\
\hline & & b. Motorable roads & Low & \\
\hline & & c. Communication facility & High & \\
\hline & & d. Health facility & High & * \\
\hline & & e. Meeting on community development & Medium & \\
\hline \multirow{5}{*}{ E.Culture } & 1. Culture & a. Worship of God & Medjum & \\
\hline & \multirow{2}{*}{ 2. Labor } & a. Labor force availability & High & \\
\hline & & b. Family planning & Low & \\
\hline & \multirow{2}{*}{ 3. Education } & a. Educationof children & Medium & $*$ \\
\hline & & b. Self education & Low & \\
\hline \multirow{2}{*}{ F.Livelihood security } & 1. Cash & a. Cash income & Low & \\
\hline & 2. Kind & a. Food availability & High & $*$ \\
\hline
\end{tabular}

and drinking water availability. The GMK households have a high degree of concern for cash income, irrigation, food, crop productivity, and forest resources. The low caste KDS households place their highest degree of concern for cash income, food, fodder availability, fuelwood availability and drinking water availability.

\section{RELATIONSHIP BETWEEN SOCIOECONOMIC CONDITIONS OF THE CASTE/ETHNIC GROUPS AND THEIR CONCERNS}

Categorization of people's concerns

i) General categorization:

Since there are too many variables for individual observation, it was necessary to categorize them into manageable numbers. A correlation matrix was constructed for all the concerns (Table 4 ). An initial grouping was done based on the highest correlation. As a result the concerns have been categorized into the following nine groups.

I . Fodder availability

Fuelwood availability

Forest Resources

II. Crop productivity Irrigation

III. Motorable roads Communication facilities

IV. Landslides and soil erosion Maintenance of terraces Floods

$\mathrm{V}$. Meeting on community development Electricity supply

Health

VI. Family planning Education of children Self education

VII. Cash income Food availability

VIII. Worship of God 


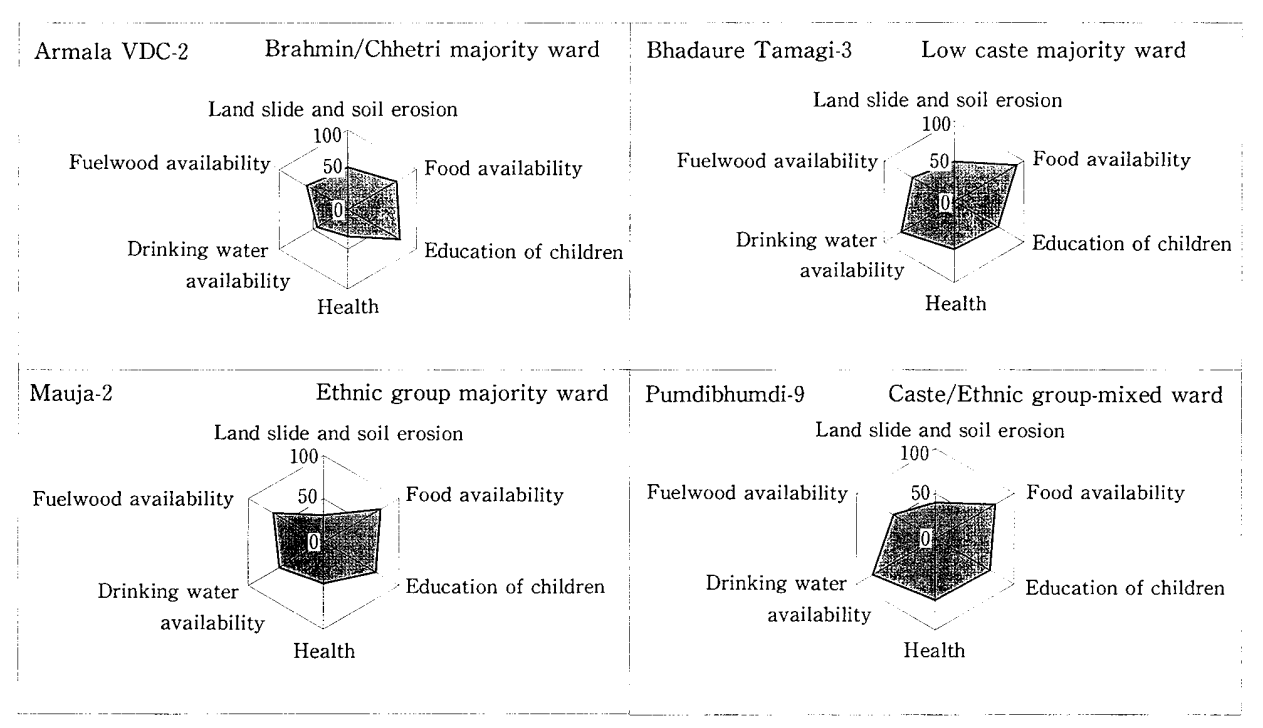

Fig. 3 Degree of concern of caste/ethnic households

Labor force availability

IX. Drinking water supply

Foot trails

ii Categorization for radar chart analysis:

Radar chart analysis has been done in order to understand the characteristics, especially the needs, of the individual wards. There are nine wards in a VDC. There are 144 wards from 19 VDCs covered by the study. Each ward comprises of 32 to 160 households covering an average area of 196 ha $(5.3-1,199$ ha).

The concerns were further categorized into agriculture, forestry, drinking water, infrastructure, culture and livelihood security (Table 5 ). Wherever appropriate, subcategories have been formed under the main categories. For example agriculture is further divided into productivity and erosion subcategories. Concern for crop production and irrigation are included in the productivity subcategory, while the concerns for landslides and floods have been included in the erosion subcategory. One representative concern from each group was selected according to their degree of variance and relative importance in the group. The selected concerns are food availability, health facilities, education of children, landslides and soil erosion, fuelwood availability and drinking water availability.

Among the above six variables considered for the construction of radar chart, concerns for food availability, education of children and health care facilities are considered as the ones related to socioeconomic aspects. On the other hand, landslides and soil erosion, drinking water availability, and fuelwood availability are considered as the concerns related to natural resources aspects.

Generally the people are more concerned with the socioeconomic aspects (Fig. 3 ). However, there is wide variation among the VDCs and the wards within the VDC as well. In Thumki VDC, the radar chart is sharply tapered towards the natural resources side because of high concern for drinking water availability, although there is more shaded area on the socioeconomic side. In Mauja VDC, the shaded area in the radar chart forms closer to a rectangular shape with relatively moderate scores for all concerns. Two distinct trends are observed in this VDC. The ward nos. $2,3,4,5$ and 6 have low concern for landslides, while the others have high concern for landslides and soil erosion. Among them, wards 2, 3, 5 and 6 are ethnic group majority wards, and ward 4 is a low caste majority ward.

The Armala VDC has greater concern for fuelwood in ward no 7,8 and 9. Armala-7 is an ethnic group majority ward, and Armala- 8 and 9 are low caste majority wards, and these groups have only limited access to forest resources. Although the walking distance to fuelwood forest is shorter than other wards, difficult access to fuelwood forest can be the reason for high concern for fuelwood availability. All the wards have a large shaded area for socioeconomic concerns. In most of the wards of the Pumdi Bhumdi VDC, the radar chart is tapered to the socioeconomic side with high concern for food availability. In the Bhadaure Tamagi VDC there is high concern for landslides.

Adoption of an appropriate strategy for watershed management depends upon the characteristics of each ward. In this context it is desirable to have an understanding of the factors which influence the people's concerns.

Factors influencing people's concerns

Stepwise regression analysis has been conducted in order to determine the factors influencing the concerns for 
the availability of fuelwood and food.

i ) Possible predictor variables considered for regression analysis:

$X_{1}$-Shortage of cereals-months/yr/household (hh)

$X_{2}$-Illiteracy-\% of economically active population in the ward without any formal education

$X_{3}$-Livestock population-head/hh (cows, buffalo and goats)

$X_{4}$-Ownership of Bariland-ha/hh

$X_{5}$-Ownership of Khetland-ha/hh

$X_{6}$ - Total Khetland-total area of Khetland-owned and rented ha/hh.

$X_{7}$-Total Bariland-total area of Bariland-owned and rented ha/hh.

$X_{8}$-Absentee family members-\% in the ward

$X_{9}$-Production of paddy $-\mathrm{kg} / \mathrm{yr} / \mathrm{hh}$

$X_{10}$-Production of wheat $-\mathrm{kg} / \mathrm{yr} / \mathrm{hh}$

$X_{11}$-Production of maize- $\mathrm{kg} / \mathrm{yr} / \mathrm{hh}$

$X_{12}$-Production of millet-kg/yr/hh

$X_{13}$-Flood damage-ha/hh

$X_{14}$-Landslide damage-ha/hh

$X_{15}$-Ownership of horticultural trees-no./hh

$X_{16}$-Walking distance to piped water in dry seasonminutes

$X_{17}$-Walking distance to piped water in wet seasonminutes

$X_{18}$-Walking distance to spring water in dry seasonminutes

$X_{19}$-Walking distance to spring water in wet seasonminutes

$X_{20}$-Walking distance to river water in dry seasonminutes

$X_{21}$-Walking distance to river water in dry seasonminutes

$X_{22}-$ Participation in community forest-\% of members in the ward

$X_{23}$-No. of trees on farmland-no./hh (horticultural, fodder, fuelwood and timber trees)

$X_{24}$-One-way walking distance to fuelwood forestminutes

$X_{25}$-Forest area in the ward-ha

$X_{26}$-Proportion of forest area (\%)

$X_{27}$-Population of the ward

Fuelwood availability

Regression model for degree of concern for fuelwood availability:

$C F W=65.824+0.217 X_{24}-116.629 X_{7}+0.083 X_{22}-20.526 X_{6}+0.020 X_{11}$ $(t=11.220) \quad(t=5.798) \quad(t=-6.005) \quad(t=2.8) \quad(t=-2.616) \quad(t=2.016)$ where

$C F W=$ Concern for fuelwood availability (score)

Regression statistics:

$$
\begin{array}{ll}
R & =0.705 \\
R \text { square } & =0.497 \\
\text { Adjusted } R \text { square } & =0.478 \\
\text { Standard error } & =12.8312
\end{array}
$$

The above model suggests that area of total Bariland is the most influential predictor variable (negatively) of the concern for fuelwood availability, followed by walking distance to fuelwood forest (positively). Fodder and fuelwood trees are traditionally grown in the Bariland. Therefore, it is natural to have such an influence in the regression model. Although the Khetland is almost devoid of any trees, ownership of Khetland also has a negative effect on the concern for the fuelwood availability. Membership of households in community forests is positively related with the concern for fuelwood availability.

Food availability

Regression model for degree of concern for food availability: $C F A=47.142+5.636 X_{1}+1.269 X_{3}-0.009 X_{9}-0.088 X_{24}+0.261 X_{2}-0.176 X_{17}$ $(t=7.036)(t=8.705)(t=2.530)(t=-3.156)(t=-3.420)(t=2.927)(t=-2.179)$ where

$C F A=$ Concern for food availability (score)

Regression statistics:

$\begin{array}{ll}R & =0.779 \\ R \text { squared } & =0.606 \\ \text { Adjusted } R \text { squared } & =0.589 \\ \text { Standard error } & =8.4091\end{array}$

Shortage of cereals is the most important predictor variable for concern for food availability. Production of paddy has a negative effect on the degree of concern for food availability, but illiteracy and livestock have a positive effect. Illiteracy is negatively correlated with production of paddy, maize, millet; tree ownership etc. The poor households, especially the low castes, have little opportunity to get education. In the study area, the illiterate male household members comprise $44 \%$ in low caste households compared to $18.4 \%$ and $14.6 \%$ in the GMK and $\mathrm{BC}$ households respectively. The situation is worse in the case of females who are $81 \%$ illiterate in low caste households and $51 \%$ in the GMK and $\mathrm{BC}$ households. Therefore it is normal to have increasing concern for food availability with a higher percentage of illiterate households in the ward.

Lack of productive livestock can be one of the reasons for a positive relation between concern for food availability and number of livestock. Walking distance to piped water in wet season is negatively related. Walking distance to the fuelwood forest is also negatively related with the degree of concern for food availability. Although the effect is very marginal, the probable reasons could be that those who have settled on the lower parts of the hills with more level terraces have a greater walking distance to the forest. 


\section{IMPLICATION FOR SUITABLE WATERSHED MANAGEMENT}

Appropriate watershed management is fundamental to stabilize the physical environment and to increase the productivity of the watershed resources. The Forest Act (1993) emphasizes the direct involvement of the local users in forest management in the form of community forests. People's participation is a fundamental strategy in watershed management (DSCWM, 1993).

An important assumption is that all the users of community forests are equal-a description made from the perspective of the membership pattern. Also, in watershed management the local people are required to contribute unskilled labor in order to implement various activities. Here also it is assumed that everybody can participate equally.

This study was based on the hypothesis that people's concerns are based on their socioeconomic background and the incentive for participation would come from the reflection of their concern in the proposed activities. The analysis in this study revealed that there is an apparent gap among the caste/ethnic groups regarding their socioeconomic condition. The gap is particularly wide between the upper castes/ethnic groups and the lower caste households.

The lower caste households have less farmland than the high caste and ethnic group. As found in the regression analysis, Bariland is the most important factor for concern about fuelwood availability. The less Bariland, the greater the concern for the fuelwood availability. Also the walking distance to the fuelwood forest, which is another important factor, is higher for the KDS households, and so concern for fuelwood availability is higher for them.

When the national forests are handed over to the users' groups, they impose strict rules about product harvesting and access to forests (GRANER 1997). Quite often, access to forests is allowed only for a limited time of the year. It was observed in the Armala VDC that the forests are generally open for about two months in the winter i.e. January-February. The forest users told the authors that that is free time without major agricultural operations. However, the specific time for opening is further decided by each forest users' committee. In one of the community forests where the low castes are also members, the forest is open only for two days.

The low caste people who cannot supply much of their own forest products other than from community forests suffer the most due to long closure of the forest. In the absence of viable alternatives, the lower castes have to resort to illegal means to obtain forest products which leads to social conflicts. On the other hand, BC and GMK households may obtain fuelwood from their private land.
Conflicts in community forests have already appeared, partly because of lack of involvement of low caste households (Poudel, 1996). This is particularly significant when more and more forests are being brought under community management.

Within a VDC, most of the activities are conducted on a ward basis. So it is important to know the characteristics of each ward regarding the people's needs. The radar chart analysis showed that generally the needs are more for socioeconomic aspects such as food availability, health facility and education of children. This means that people will be more attracted to the activities which help to solve the problem of food availability. Radar charts show that food availability is a high concern for the KDS majority wards whereas education of children is a bigger concern in the $\mathrm{BC}$ majority wards. Thus it is important to implement watershed management activities based on the characteristics of the particular ward or community.

It is obvious that since the low caste households own less farmland, they have more concern for food availability. The low caste households produce only $43 \%$ of cereals compared with the high caste households. Regression analysis also revealed that shortage of cereals is the biggest predictor variable for food availability. The shortage of cereals is more prominent for those who have lower crop production. Illiteracy is another factor which increases concern for food availability. There is negative correlation between the percentage of illiterate population in the ward and the ownership of Khetland $(-0.33)$ and Bariland $(-0.27)$. Eradication of illiteracy would lead to wider vision and enhance the analytical capabilities of the local people to find alternatives for income generation. Therefore, stronger measures for the education of local people are needed.

Lower crop production, which is partly related to ownership of fewer livestock, means that low caste households have to spend more time to solve their hand-to-mouth problems of daily survival. In such cases they will not have enough incentive to participate in watershed management activities which do not bring benefit in a short period. Any watershed management activity that emphasizes farmland does not contribute much to the benefit of the low caste people.

The upper castes have more stable sources of income compared to the low castes who mainly depend upon their temporary wage labor to solve their hand-to-mouth problem. It is evident from the analysis that the low caste people have the highest degree of concern for cash income. Therefore the lower castes will be more interested in income-generating activities which bring benefit in the short term. Only then we can expect them to participate in the activities related to forest/watershed conservation. It is necessary to implement income-generating activities in view of their socioeconomic condition. 
One of their greatest daily concerns is the fetching of drinking water and fuelwood. It is important to consider how to reduce the time taken for these activities. This will not only reduce the burden of women but also allow them to be involved in other productive works. Piped water supply, as observed in the above analysis, has been quite effective in reducing the time taken to fetch drinking water.

Very little attention has been paid to the socioeconomic condition of the local people in watershed management planning (Dscwm, 1996). However, in the participatory approach it is important that households of all castes take part in the watershed management program. So unless we consider such differences, the low caste people will have less incentive to participate in watershed management activities. This will jeopardize the essence of the participatory approach of involving disadvantaged groups in the watershed management program and will limit the chance of improving their livelihood.

\section{CONCLUSION}

The present policy measures pertaining to forest watershed conservation have defined the local people by a single word 'user'. It is also assumed that all users can participate equally. The analysis in this study, however, revealed that even if the users are similar in their use of a particular resource, there is a wide gap among them in terms of their socioeconomic condition. This gap reflects their caste/ethnic background-the traditional social structure in Nepal.

Statistical analysis showed that the ownership of farmland is an important factor in relation to concerns about food and fuelwood availability. Those who do not own much farmland have high concern. For them the public forests are an important source of fuelwood and other forest products.

Relatively stable sources of income for the upper castes and ethnic groups place them in a better position than the lower caste households who have to depend on their daily wage labor. If the households have to spend their daily time in wage labor, they cannot be expected to participate in watershed management by making contributions for free. Also they have to spend more time in collection of fuelwood and drinking water which limits their opportunity to participate in watershed management activities. Their high concern for cash income necessitates implementation of a wide range of measures to improve their livelihood. In particular, income-generating activities need to be implemented in view of their socioeconomic condition.

It is important that these concerns of the local people be considered while undertaking various watershed management activities in order to improve their livelihood together with promotion of environmental conservation, even if such endeavors entail changes in the existing policy framework. In order to avoid conflicts and ensure equity in resource distribution, policy arrangements must ensure that the socially and economically disadvantaged people get a fair share.

\section{ACKNOWLEDGEMENTS}

The authors extend their sincere acknowledgements to Professor Dr. Mitsuhiro Minowa for his valuable comments and to JICA for giving permission to use their database for this study.

\section{LITERATURE CITED}

Achet, S. H., (1998): A framework for participatory integrated resource management standards for the mountain areas: lessons from watershed management in Nepal, 20pp

BistA, D. B., (1991): Fatalism and development : Nepal's struggle for modernization. Orient Longman Ltd., India, 186pp

Bista, D. B., (1996): People of Nepal. Ratna Pustak Bhandar, Kathmandu, 218pp

Central Bureau of Statistics, (1996): Statistical pocket book of Nepal. Central Bureau of Statistics, Kathmandu, 327pp

Central Bureau of Statistics, (1997): Statistical year book of Nepal. Central Bureau of Statistics, Kathmandu, 403pp

Evans, C., (1997): Qualitative evaluation report of the Begnas Tal RupaTal Watershed Management Project (BTRT) for CARENepal, Kathmandu, 25pp

GRANER, E. (1997): The political ecology of community forestry in Nepal. Verlag fur Entwicklungspolitik Saarbrucken, Germany, 372 $\mathrm{pp}$

JiCA/Department of Forestry and Water Resources Development, (1997): Conservation of forest resources based on local people's initiatives JICA, 127pp (in Japanese)

JICA/HMG, (1998): The development study on integrated watershed management in the Western Hills of Nepal Socioeconomic Baseline Survey main report. Japan Forest Technical Association (JAFTA) Kokusaikogyo Co. Ltd., 237pp

Kadota, T. and Nishioka, Y., (1994): Needs of the people in the Nepal hill areas and forestry extension. The Tropical Forestry New Series 30: 2-13(in Japanese)

Kayastha, B. N., Bajracharya, K. M. and Shreshtha, A., (1997): Final evaluation Begnas Tal Rupa Tal (BTRT) Watershed Management Project. CARE Nepal Department of Soil Conservation and Watershed Management, Kathmandu, 74pp

Mahat, T. B. S., Griffin, D. M. and Shepherd, K. R., (1986): Human impact on some of the forests of the Middle Hills of Nepal. Part-1, Mountain Research and Development 6 (3): 223-232

Meiman, J. R., Amatya, D. B., Hawkes, E. G., Shakya, P. M. and Seifman, R. M., (1985): Evaluation report Resource Conservation and Utilization Project Nepal. International Science and Technology, Inc. Washington, D.C., 222pp

Ministry of Foreign Affairs/DANIDA, (1997): Natural Resource Management Sector Assistance Program (NARMSAP) Component 
Descriptions. Ministry of Foreign Affairs/DANIDA, Kathmandu, 88 $\mathrm{pp}$

Nagame, I., (1997): Assignment Termination Report. Japan International Cooperation Agency, 30pp

PoudeL, C. K., (1997): Conflicts in two community forestry user groups at Kaski District. Nepal Banko Janakari 7 (1): 23-27

Sthaptт, K. M., (1989): Soil Conservation Status in Nepal. Mrs. S.
Sthapit, Lalitpur, Nepal, 87pp

WAGLEY, M. P., (1997): Status of watershed management in Nepal (in Sharma P. N. and Wagley M. P. (Eds.) (1997): Status of Watershed Management in Asia). Netherlands/UNDP/FAO GCP/RAS/161 NET-RAS/93/062 29-34, 82pp

(Received 21 March 2000) (Accepted 20 June 2000) 